\title{
NOTICIAS EN TORNO AL PINTOR ANTONIO DE TORRES EN EL ARCHIVO DEL SAGRARIO METROPOLITANO
}

\section{Rogelio Ruíz GoMAR}

En el número anterior de los Anales del Instituto de Investigaciones Estéticas la maestra Mina Ramírez Montes dio a conocer dos importantes documentos en relación con el pintor Antonio de Torres que localizara en el Archivo General de la Nación. ${ }^{1}$ El primero, el testamento otorgado por el pintor en el año de 1722, en el que se declara hijo de Tomás de Torres y Lorenzana y de María Rodríguez, estar casado con Inés de Córdova y sólo haber procreado una hija, Inés de Torres, a la sazón ya casada con don Pedro de Zúñiga y Rivero.

El segundo documento es el recibo que otorgó la hija del pintor en agosto de 1731 a María Millán -esposa de éste- de los bienes que habían quedado a la muerte de aquél. Dato que le permitió inferir a la maestra Ramírez Montes que, recuperado de los achaques, Antonio de Torres debió enviudar y contraer segundas nupcias y, asimismo, establecer la fecha de la muerte de aquél en ese mismo año.

Respecto al testamento, resulta interesante destacar que para cumplir con lo establecido en él, Antonio de Torres nombró como albaceas a su esposa - que lo era entonces Inés de Córdova-, a su yerno Pedro de Zúñiga y Rivero y al también pintor Juan Rodríguez Juárez. La designación de este último no deja de llamar nuestra atención, pero lo cierto es que no tiene nada de particular; empero, lo que sí merece subrayarse es el hecho de que claramente le menciona como "primo" suyo. A la vista de este inesperado y hasta entonces ignorado vínculo familiar entre estos conocidos pintores, la maestra Ramírez Montes deduce que el parestesco se debía a que la madre de Antonio de Torres - en el testamento designada como María Rodríguez- era "seguramente" hermana de Antonio Rodríguez, padre, como sabemos, de los afamados pintores novohispanos Juan y Nicolás Rodríguez Juárez.

Para corroborar este punto y de paso contribuir al mejor conocimiento tanto de la vida de Antonio de Torres como de su relación familiar con

1 Mina Ramírez Montes, "El testamento del pintor Antonio de Torres", en Ana" les del Instituto de Investigaciones Estéticas, vol. XV, núm. 59, México, Universidad Nacional Autónoma de México, 1988, pp. 265-272. 
los Rodríguez Juárez, y en general de la de su entorno familiar, he reunido las siguientes noticias, mismas que tienen el común denominador de haber sido extraídas de ese rico acervo, no siempre bien aprovechado, que es el Archivo del Sagrario Metropolitano. ${ }^{2}$ En justicia habria que advertir que se trata de material documental que no es en sentido estricto de carácter artístico, pero considero que tales noticias vienen a enriquecer la información que poseemos sobre este pintor, el cual, como la mayoría de los pinceles activos en la Nueva España, sigue en la espera de un buen estudio monográfico.

Convendría comenzar esta revisión con el matrimonio de los abuelos maternos. En enero de 1636 casaban en la ciudad de México Sebastián Rodríguez, natural de la villa de Alcalá, en España, e Isabel Beltrán de los Reyes. ${ }^{3}$ De este matrimonio habrían de nacer María, Antonio, Catalina y Josefa. Tal y como solía acostumbrarse en el periodo virreinal, las hijas habrían de usar con más frecuencia el apellido de la madre, en tanto que el hijo el apellido del padre. Por esta razón, aunque hermanos, aquellas aparecerán consignadas las más de la veces con los apellidos maternos de Beltrán de los Reyes, al tiempo que a Antonio le encontraremos siempre con el apellido paterno de Rodríguez. Luego tenía razón la maestra Ramírez Montes al aventurar que la madre de Antonio de Torres había sido hermana del también pintor Antonio Rodríguez, padre, como ya se ha dicho, de Nicolás y Juan Rodríguez Juárez. (Ver cuadro 1).

De la primera hija, María Beltrán de los Reyes, la futura madre de Antonio, de Torres, se corrieron amonestaciones en noviembre del año de 1653 para el matrimonio que iba a contraer con Diego de Siria. ${ }^{4}$ Sin embargo, todo parece indicar que dicho enlace no se llevó a cabo, toda vez que a mediados de enero de 1655 la encontramos próxima a casarse con Tomás de Torres (Documento 1), cuyo nombre completo era Tomás de Torres y Lorenzana. ${ }^{5}$

2 Deseo expresar desde aquí mi agradecimiento al Pbro. Rubén Avila Enríquez, pártoco del Sagrario, al señor Ricardo Gracida, administrador del mismo, y a todás las personas que en él laboran, por las facilidades prestadas para la consulta e investigación de $\tan$ valioso acervo bajo su custodia.

3 Vid. Archivo del Sagrario Metropolitano, Libro 4 de comonestaciones de españoles, 1634-1640, f. 21.

4 Hijo de Pedro de Siria e Isabel Ruiz de Villegas; ASM, Libro 7 de amonestaciones de españoles, 1653-1656, f. $13 \mathrm{v}$.

5 En virtud de que se le menciona como "hijo de la Iglesia", desconocemos quiénes fueron sus padres, pero dado el empleo de los mismos apellidos, cabe pensar que era pariente cercano, acaso hermano, del maestro de platero Francisco de Torres y Lorenzana, quien recibía en el año de 1695 un aprendiz; pero más 
De este enlace habrían de nacer por lo menos cinco hijos, el cuarto de los cuales sería precisamente Antonio de Torres, el pintor que nos ocupa. El primer hijo, al que bautizaron con el nombre de Roque, debió de nacer hacia 1660, ya que, como veremos más adelante, para 1680 iba a casarse. Al segundo le pusieron por nombre Sebastián y fue bautizado en febrero de 1663 (Documento 2). Después vendría una hija a la que en marzo de 1665 pusieron por nombre Paula (Documento 3). En abril de 1667 fue llevado a bautizar el futuro pintor Antonio de Torres (Documento 4). Y finalmente, en octubre de 1670 otro hijo, al que llamaron Francisco (Documento 5).

Por su parte, como es bien sabido, Antonio Rodríguez contrajo matrimonio con Antonia Juárez, hija de su maestro, el célebre pintor José Juárez, en septiembre del año de 1659. Matrimonio bastante prolífico, por cuanto que habrían de tener trece hijos, la mayoría de los cuales debieron morir de muy corta edad, y de entre los cuales destacan los ya mencionados Nicolás y Juan Rodríguez Juárez. Al respecto resulta interesante advertir que, por más que se antojaba que era más joven Antonio de Torres, en realidad era de la misma edad que su primo Nicolás, el mayor de aquél par de famosos hermanos; habida cuenta de que fueron llevados a bautizar en el mismo año de 1667, con diferencia de tan sólo tres meses: Nicolás en enero y Antonio de Torres en abril.

De las otras hermanas de la madre de Antonio de Torres tengo las siguientes noticias. Catalina Beltrán de los Reyes casó con Antonio de Torres y Moreira, en marzo de $1663 .{ }^{6}$ Entre 1664 y 1677 llevaron a bautizar a seis hijos: Feliciana, Manuela, Micaela, Antonia - de quien fue padrino Antonio Rodríguez-, Isabel y María. ${ }^{7}$ Tras la muerte del marido, Catalina Beltrán de los Reyes casó en segundas nupcias a mediados de 1681

aún del Nicolás de Torres y Lorenzana, quien, junto con su segunda esposa, María de la Cerna, aparece como padrino de una hija de aquél (Documento 3). Vivía en la calle de la Merced y su esposa, María Rodríguez que murió el 7 de septiembre de 1677, fue enterrada en San Agustín (ASM, Libro 1 de defunciones de españoles, $1671-1680$, f. $216 \mathrm{v}$.

- Era hijo de Pedro de Moreira y Torres y doña Antonia de Lafuente; ASM, Libro 9 de amonestaciones de españoles, 1662-1666, f. 17 y Libro 8 de matrimonios de españoles, 1657-1667, f. 169 v. Es posible que el celebrante en la boda, fray Juan de "Morera", haya sido pariente del contrayente. Tras enviudar, Catalina Beltrán de los Reyes contraería un segundo matrimonio con el licenciado don Juan de Vergara, el 29 de junio de 1681; vid, infra, nota 8.

7 Vid. ASM, Libro 21 de bautismos de españoles, 1663-1667, f. 90 y f. 247; Libro 22 de bautismos de españoles, 1667-1669, f. 174; Libro 23 de bautismos de españoles, 1670-1672, f. 149, y Libro 25 de bautismos de españoles, 1674-1679, f. 6 y f. 201 . Manuela murió apenas cumplidos los 12 años, el 27 de abril de 
con el licenciado Juan de Vergara; ${ }^{8}$ pero este matrimonio duró muy poco, pues para finales del año siguiente, el dicho Juan Vergara, ya viudo, estaba próximo a contraer nuevo enlace. ${ }^{9}$ Por último, a finales de 1664 corrieron las amonestaciones para el matrimonio entre Josefa Beltrán de los Reyes y Antonio Martín Cataño ${ }^{10}$ De este matrimonio sólo tengo noticia de dos hijas: Josefa de la Encarnación, bautizada el 28 de marzo de 1666, cuyos padrinos fueron los padres de Antonio de Torres (Documento 6), y María, bautizada el 18 de abril de $1668,{ }^{11}$ cuyos padrinos fueron los padres de los Rodríguez Juárez.

Pero vengamos de nueva cuenta con nuestro pintor. Apenas cumplidos los 19 años, Antonio de Torres contrajo matrimonio con Inés de Córdova, hija de don Diego de Córdova y de María Días de Pliego. Las amonestaciones corrieron en agosto de 1686 (Documento 7) y el matrimonio se celebró el 8 de septiembre de ese mismo año (Documento 8). La única hija que tuvieron y a la que pusieron por nombre Inés Josefa, fue llevada a bautizar el 6 de julio de 1687 (Documento 9).

Por otra parte, Antonio de Torres y su esposa aparecen en junio de

1678; la partida de defunción nos informa que para entonces la familia vivía cerca de Santa Clara (ASM, Libro 1 de defunciones de españoles, 1671-1680, $\mathbf{f}_{.2} 251$ ). Acaso la tercera hija es la Micaela de Torres que casa en marzo de 1688 con José Velasques y Aliaga; matrimonio en el que ofició el bachiller Félix Juárez, quien era hijo de José Juárez, hermano de Antonia Juárez y, por tanto, tío de aquélla (ASM, Libro 11 de matrimonios de españoles, $1680-1688, \mathrm{f}_{.} 363 \mathrm{v}$ ). por otro lado, el 5 de febrero de 1714 se llevó a cabo el matrimonio de Isabel de Torres con José Ponce de León - viudo de Javiera Manuela de la Encarnación-; ofició el primo de la contrayente, nuestro conocido Nicolás Rodríguez Juárez, ya en su calidad de clérigo (ASM, Libro 16 de amonestaciones de españoles, 17061714 , f. 181, y Libro 15 de matrimonios de españoles, 1713-1720, f. 8). La boda, según consta en la partida correspondiente, se verificó "en casa de Antonio de Torres". Este parecería ser Antonio de Torres y Moreira, el padre de la novia, pero como se recordará, éste murió antes de 1681 , año en que veíamos a Catalina Beltrán de los Reyes contrayendo su segundo matrimonio (ver nota anterior). Así las cosas, cabría pensar que la casa en que se celebró aquella boda era la del pintor que nos ocupa: Antonio de Torres y Lorenzana Finalmente, es factible que la última de las hijas sea la María de Torres "doncella" que murió en abril de 1698 y de la que se dice vivía en la calle de San Francisco, en cuya iglesia se enterró (ASM, Libro 4 de defunciones de españoles, 1693-1698, f. 292 v.).

8 ASM, Libro 12 de amonestaciones de españoles, 1680-1687, f. 18, y Libro 11 de matrimonios de españoles, 1680-1688, f. 48.

9 ASM, Libro 12 de amonestaciones de españoles, 1680-1687, f.. 52 v.

10 Era hijo de Juan Marín Cataño y Juana Ramírez; vid. AMS, Libro 9 de amonestaciones de españoles, 1662-1666, f. 48 v., el matrimonio se verificó el 27 de diciembre de ese mismo año de 1664 (ASM, Libro 8 de matrimonios de españoles, 1657-1667, f, 224).

11 ASM, Libro 22 de bautismos de españoles, 1667-1669, f. 71. 
DOI: http://dx.doi.org/10.22201/iie.18703062e.1989.60.1527

CUADRO 1

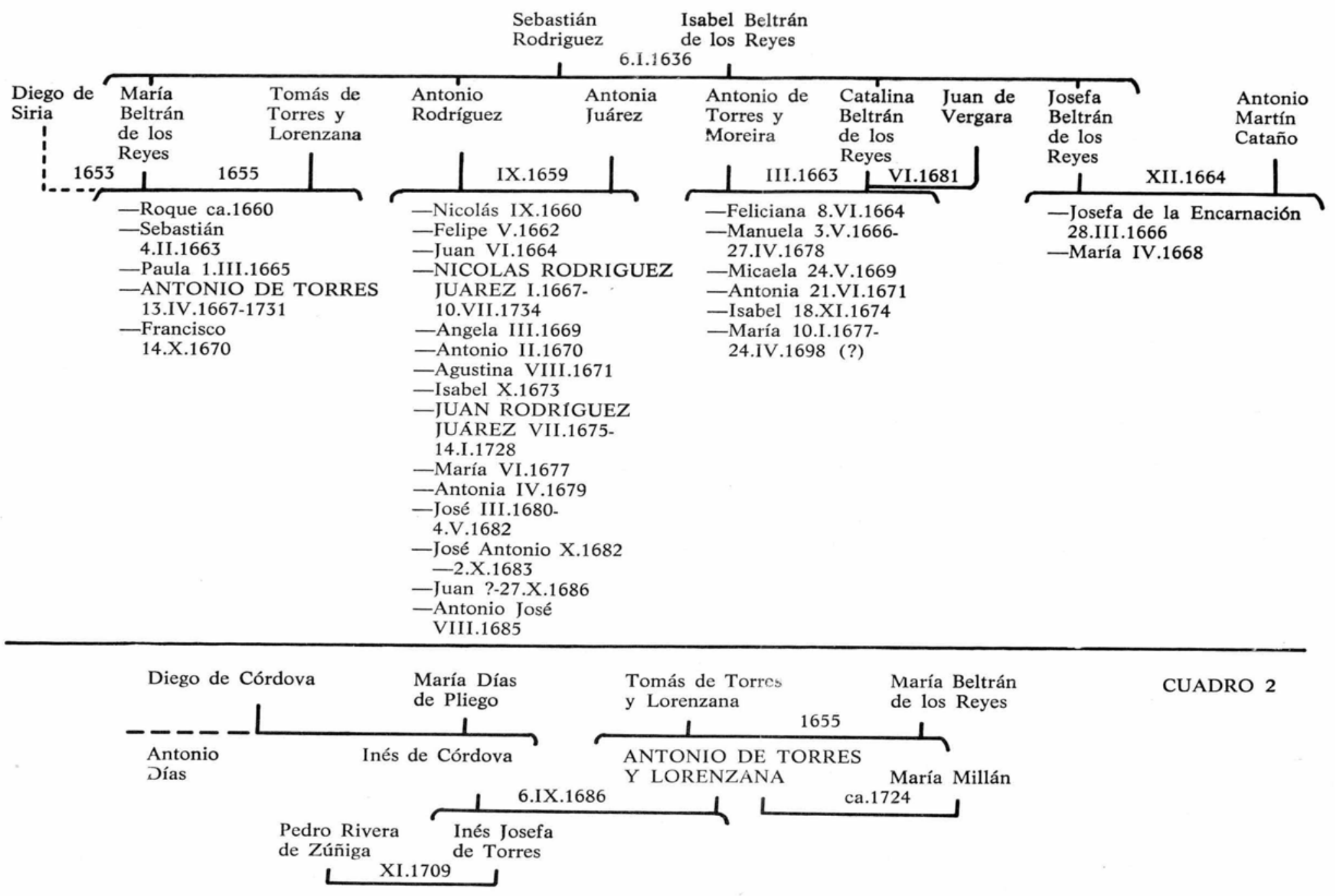


1694, junio de 1704 y noviembre de este mismo año, como padrinos en el bautizo de una niña, un niño y otra niña respectivamente, pero la verdad es que salvo en el caso del segundo, que era hijo de Juan Sánchez Salmerón, hijo a su vez del conocido pintor del mismo nombre, con quien quizá cultivaron cierto trato extrartístico, desconozco qué tipo de relación - si familiar o simplemente afectiva- los ligaba para con los padres de dichas criaturas (Documentos 10, 11 y 12).$^{12}$ Lo mismo ocurre cuando lo vemos como testigo en una boda, misma en la que ofició su primo el "bachiller" Nicolás Rodríguez Juárez. ${ }^{13}$

Sin descontar la posibilidad de que se trate de un homónimo, quiero recoger la noticia del "maestro Antonio de Torres" que aparece como testigo en otra boda. ${ }^{14}$ Por el contrario, resulta obvio que tanto el Antonio de Torres que estaba casado con Ignacia Guzmán y que muere en junio de 1705, o el casado con Catalina de Celis y que muere en 1707, así como el que casa en septiembre de 1708 con Gertrudis de Prado, son simples homónimos. ${ }^{15}$

La hija del pintor, como ya sabemos, casó con Pedro Rivero de Zúñiga, el cual era viudo de María de Esquivel; las amonestaciones corrieron a finales de noviembre de 1709 (Documento 13) y por lo que se lee en la nota marginal de dicha partida, la boda la celebró fray Antonio Pinto, religioso de la orden de Santo Domingo, el 10 de diciembre de ese año. (Ver cuadro 2).

Unos años después se realizó la boda de Manuel Rivero de Zúñiga con doña Micaela Ruiz de las Ruelas. Al parecer el contrayente era hermano del yerno de nuestro pintor, lo que explica que el propio Antonio de Torres aparezca como testigo al lado del mismo Pedro de Zúñiga, en cuya

12 Es posible que el Antonio Días, padre de la niña Josefa Gertrudis, que fue bautizada en junio de 1694 (Documento 10), hubiese sido hermano de la esposa del pintor, pues como se recordará, la madre de ella era María Días de Pliego. En este caso, ella hubiera usado el apellido paterno de Córdoba y él el Días materno.

${ }^{13}$ La boda fue entre Juan Leandro Gómez y María López; vid. ASM, Libro 14 de matrimonios de españoles, 1702-1713, $\mathrm{f}_{*} 277$.

14 En la boda de don Manuel de Frías con doña Micaela Gómez Pina; ASM, Libro 15 de matrimonios de españoles, 1713-1720, f. 107.

15 ASM, Libro 5 de defunciones de españoles, $1698-1707$, f. 311 v y f. 383 v, y Libro 14 de matrimonios de españoles, 1702-1713, f. 203 v. Con más razón concluimos que eran simples homónimos el Antonio de Torres mestizo, de 16 años, que entra en 1686 como aprendiz de carpintero de lo blanco, o aquel otro, natural de Xochimilco y que después de haber sido vecino de la ciudad de México y de la de Zacatecas, regresó a la de México para casarse con doña María López Zapata, en mayo de 1725. 
casa, ubicada en la calle de San Francisco, se verificó la ceremonia. Y para que todo quedase en familia, ofició en la misma el bachiller y pintor Nicolás Rodríguez Juárez (Documento 14).$^{16}$

Además de las correspondientes partidas de bautizo, poco es lo que puedo agregar en torno a los hermanos de Antonio de Torres. Así, por ejemplo, Roque de Torres pretendía casarse en 1680 con Teresa Sánchez; como las amonestaciones correspondientes corrieron en el mes de agosto de $1680,{ }^{17}$ podemos inferir que era el hermano mayor, pues para entonces debía contar por lo menos con 20 años de edad, lo que nos lleva a aceptar que debió nacer alrededor de 1660 . Por otro lado, su hermana Paula de Torres casó el 31 de julio de 1684 con Francisco de Luna -viudo de María Galván-, y tras enviudar muñó el 1 de julio de $1703^{18}$

Soy consciente de que estas noticias, más que al conocimiento del "pintor", vienen a enriquecer la información en torno al "hombre"; pero no debemos olvidar que los artistas, en cuanto hombres de carne y hueso, son seres que nacen, crecen, se relacionan con su entorno familiar y social, y llegado el momento se casan, tienen hijos y finalmente mueren, no sin antes haber vivido momentos felices y sufrido penas físicas 0 morales, exactamente igual que cualquier mortal; y no se podrá negar que el conocimiento de estos detalles aparentemente intrascendentes para la historia del arte, nos pueden ayudar a comprender mejor su actuación. Así, por ejemplo, aunque faltaría constatar en qué grado influyó reaimente para la inclinación de Antonio de Torres hacia el arte de la pintura, me parece que pudo ser decisiva la presencia tan cercana de su tío Antonio Rodríguez, con quien incluso es posible ahora pensar que llevó a cabo su formación. Por otro lado, tales noticias nos permiten unir hilos que de otra manera nunca se nos hubiera ocurrido relacionar, verbigracia, su posible amistad para con el pintor Juan Sánchez Salmerón y los hijos de éste, o la existencia de aquel otro tío suyo, hermano de su padre, que era maestro de platero, o el hecho de que al crecer la familia por el lado de su yerno, se incorporó a ésta un maestro confitero.

Confío, pues, en que las noticias aquí reunidas sirvan de base para un

16 Igualmente familiar en algún grado debió de ser el Juan Alonso Rivero de Zúñiga, maestro confitero, poseedor en 1693 de unas casas situadas en la calle que va de la de los Donceles a la parroquia de la Santa Veracruz.

17 ASM, Libro 12 de amonestaciones de españoles, 1680-1687, f. 3.

18 Vid. ASM, Libro 12 de amonestaciones de españoles, 1680-1687, f. 95, y Libro 11 de matrimonios de españoles, 1680-1688, f. 206 v. y Libro 5 de defunciones de españoles 1698-1700, f. 208. 
estudio monográfico que dé cuenta de la vida y obra de ese interesante pintor activo en el paso del siglo XVII al XVIII que fue Antonio de Torres, cuya mejor obra es, a mi juicio, el estupendo conjunto de lienzos que, a manera de tríptico, engalana la sacristía de la iglesia del que fuera Colegio de Propaganda Fide en Guadalupe, Zacatecas.

\section{DOCUMENTO 1}

Partida de amonestación para el matrimonio de los padres de Antonio de Torres.

Thomás de Torres, natural y vecino de esta ciudad, hijo de la Iglesia, con María Beltrán de los Reyes, natural de esta ciudad, hija de Sebastián Rodrígues y de Isabel Beltrán de [enero de 1655] los Reyes

ASM, Libro 7 de amonestaciones de españoles, 1653-1656, f. 28.

\section{DOCUMENTO 2}

Partida del bautizo de Sebastián, hermano de Antonio de Torres.

Sebastián En 4 de febrero de 1663 años, con licencia del cura semanero, bauticé a Sebastián, hijo de Thomás de Torres y Maria Beltrán de los Reies; fueron sus padrinos el alferes Domingo de Torres y doña Lieja de Torres

Doctor don Isidro Sariñana Bachiller Bartolumé Fernández Pardo

ASM, Libro 20 de bautismos de españoles, 1660-1663, f. 213.

\section{DOCUMENTO 3}

Partida del bautizo de Paula, hermana de Antonio de Torres.

Paula En 1 de marzo de 1665 años, con licencia del cura semanero bauticé a Paula, hija de Thomás de Torres y de María Veltrán; fueron sus padrinos Nicolás de Torres y María de la Cerna

Diego de Villegas

Bachiller Nicolás Manosalbas y Mendoza

ASM, Libro 21 de bautismos de españoles, 1663-1667, f. 147. 


\section{DOCUMENTO 4}

Partida del bautizo de Antonio de Torres.

Antonio En 13 de abril de 1667 años, con licencia del cura [semanero], bauticé a Antonio, hijo de Thomás de Torres y Lorenzana y de María Beltrán de los Reyes; fue su padrino Juan Martínez de Alba

Melchior López Farfán

Bachiller Bartolomé Fernández Pardo

ASM, Libro 21 de bautismos de españoles, 1663-1667, f. 331.

\section{DOCUMENTO 5}

Partida del bautizo de Francisco, hermano de Antonio de Torres.

Francisco En 14 de octubre de 1670 años, con licencia del cura [semanero], bauticé a Francisco, hijo de Thomás de Torres y Lorenzana y de María Beltrán de los Reyes; fue su madrina doña Juana de An. tunez

Don Juan de Sagade Villar
Bachiller Bartolomé Fernández Pardo

ASM, Libro 23 de bautismos de españoles, 1670-1672, f. 75.

\section{DOCUMENTO 6}

Partida de bautizo en el que son padrinos los padres de Antonio de Torres.

Josepha de la En 28 de marzo de 1666 años, con licencia del cura semaneEncarnación ro, bauticé a Josepha de la Encarnación, hija de Antonio Martín Cataño y de Josepha Beltrán de los Reies; fueron sus padrinos Thomás de Torres y María Beltrán de los Reies.

Luis Fonte de Mesa

$$
\begin{gathered}
\text { Bachiller don Manuel } \\
\text { de la Cueva y Mar- } \\
\text { cha }
\end{gathered}
$$

ASM, Libro 21 de bautismos de españoles, 1663-1667, f. 239 bis.

\section{DOCUMENTO 7}

Partida de amonestación para el matrimonio de Antonio de Torres. 
[Testado: ] Licencia al padre fray Francisco del Rosal, religioso de San Francisco
Antonio de Torres, natural y vecino de esta ciudad, hijo legítimo de Thomás de Torres y de María Beltrán de los Reyes, con Inés de Córdova, natural y vecina de esta ciudad, hija legítima de don Diego de Córdoba y de María Dias de Pliego. en 24 [agosto de 1686]

ASM, Libro 12 de amonestaciones de españoles, 1680-1687, f. 142.

\section{DOCUMENTO 8}

Partida del matrimonio de Antonio de Torres.

Antonio de Torres con En 8 de septiembre de 1686 años, con licencia del Inés de Córdova bachiller don Juan de Padilla, cura teniente de esta santa iglesia catedral de México, yo fray Francisco del Rosal, religioso de Nuestro Padre San Francisco, desposé por palabras de presente que hicieron verdadero y legítimo matrimonio a Antonio de Torres con Inés de Córdova; siendo testigos don Martín Piñero, don Pedro de Córdova y don Diego del Rosal, presentes a dicho matrimonio

Bachiller don Juan de

Padilla

Fray Francisco del Rosal

ASM, Libro 11 de matrimonios de españoles, 1680-1688, f. 295.

\section{DOCUMENTO 9}

Partida de bautizo de Inés Josefa, hija de Antonio de Torres.

[Testado: Petronila; En 6 de julio de 1687 años, con licencia del cura semainterlineado: ] Inés Jos $[s i c]$ nero, bauticé a [testado: "Petronila", enmendado:] Inés Josepha, hija de Antonio de Torres y de Inés de Córdoba; fue su padrino Nicolás de Páes. enmendado Inés vale [Rúbrica.]
Don Joseph Ramírez de Arellano
Don Diego Gonsa- les de Peña- fiel

ASM, Libro 28 de bautismos de españoles, 1685-1688, f. 166 v. 


\section{DOCUMENTO 10}

Partida de bautizo en el que son padrinos Antonio de Torres y su esposa.

Josepha En 6 de junio de 1694 años, con licencia del cura semanero, bauGertrudis ticé a Josepha Gertrudis Petronila, hija de Antonio Dias y Juana de Cárdenas; fueron sus padrinos Antonio de Torres y Lorenzana y Inés de Córdova.

Don Iñigo Franco Velasques

Bachiller Salyador de Nesia (?) Claver

ASM, Libro 30 de bautismos de españoles, 1691-1695, f. 209 v.

\section{DOCUMENTO 11}

Partida de bautizo en el que son padrinos Antonio de Torres y su esposa.

Joachin En 12 de junio de 1704 años, con licencia del cura semanero, Alexandro bauticé a Joachin Alexandro, hijo legítimo del legítimo matrimonio de Juan Sánchez y de Agustina Rivera; fueron sus padrinos Antonio de Torres y Ynés de Córdova

Don Joseph de Lezamiz

Bachiller Blás Sánchez Salmerón

ASM, Libro 33 de bautismos de españoles, 1701-1705, f. 324.

\section{DOCUMENTO 12}

Partida de bautizo en el que son padrinos Antonio de Torres y su esposa.

María En 10 de noviembre de 1704 años, con licencia del cura semanero, Francisca bauticé a María Francisca, hija legítima y de legítimo matrimonio de Marcos García y de Francisca López; fueron stus padrinos Antonio de Torres y Ynés de Córdova

Doctor Joseph de Torres y Vergara

Bachiller Thomas de Coca

ASM, Libro 33 de bautismos de españoles, 1701-1705, f. 364 v.

\section{DOCUMENTO 13}

Partida de amonestación para el matrimonio de la hija de Antonio de Torres. 
[Testado: Los debe. Licencia al padre Fray Antonio Pinto de Santo Domingo, en 10 de diciembre de 1709 años.]
Pedro Ribero de Súñiga, vecino de esta ciudad, viudo de María de Esquibel, con doña Inés de Torres, española y vecina de esta ciudad, hija legítima de Antonio de Torres y de Ynés de Cordóva.

ASM, Libro 16 de amonestaciones de españoles, 1706-1714, f. 85 v.

\section{DOCUMENTO 14}

Partida de matrimonio en el que aparece como testigo Antonio de Torres.

Don Manuel Ribero de En 3 de octubre del año del Señor de 1713, habienZúñiga con doña Micae- do precedido las tres amonestaciones que el santo la Ruis de las Ruelas concilio de Trento dispone, y con licencia del doc-tor don Miguel de Zetina, cura propio de esta santa iglesia, yo el bachiller don Nicolás Rodrígues Xuares, estando en las casas de Pedro de Zúñiga, en la calle de San Francisco, desposé legítimamente por palabras de presente, a don Manuel Ribero de Zúñiga con doña Micaela Ruis de las Ruelas; fueron testigos a dicho matrimonio Antonio de Torres, don Pedro de Zúñiga y don Pedro de las Casas, presentes, todos vecinos de esta ciudad de México.

Doctor Miguel de

Bachiller Nicolás Zetina

Rodriguez Xuarez

ASM, Libro 14 de matrimonios de españoles, 1702-1713, f. 346. 